\title{
Effects of Physalis peruviana $L$ on Toxicity and Lung Cancer Induction by Nicotine Derived Nitrosamine Ketone in Rats
}

\author{
Ayman El-Meghawry El-Kenawy ${ }^{1 *}$, Said Said Elshama², Hosam-Eldin Hussein \\ Osman $^{3}$
}

\begin{abstract}
Nicotine-derived nitrosamine ketone (NNK) is considered a key tobacco smoke carcinogen inducing lung tumors. Physalis peruviana L (harankash) is considered one plant with marked health benefits. This study aimed to evaluate Physalis peruviana $\mathrm{L}$ effect on the toxic effect of NNK induced lung cancer in the rats by using pulmonary histopathological, immunohistochemical and DNA flow cytometric analyses. Sixty adult male rats were divided into four groups, each consisting of fifteen animals. The first group received saline, the second received two successive toxic doses of NNK only while the third received two successive toxic doses of NNK with a single daily dose of Physalis peruviana $\mathrm{L}$. The fourth group received a single daily dose of Physalis peruviana $\mathrm{L}$ only. Toxic doses of NNK induced hyperplasia and adenocarcinoma in the lung and positive immunoreactivity for Ki-67 and p53 staining with disturbance of the lung DNA content. Administration of Physalis peruviana L with NNK led to a mild pulmonary hyperplasia and weak expression of Ki-67 and p53 with an improvement in the lung DNA content. Physalis peruviana L may protect against NNK induced lung carcinogenesis due to its antioxidant and anti-proliferative effects.
\end{abstract}

Keywords: Lung - NNK - physalis peruviana L

Asian Pac J Cancer Prev, 16 (14), 5863-5868

\section{Introduction}

Lung cancer is considered to be one of the most common causes of death in the world, and cigarette smoke represents the most common cause of this cancer type. The tobacco smoke contains two main carcinogenic components which are polycyclic aromatic hydrocarbons and nitrosamines which have a clear correlation to lung cancer. Nitrosamine 4-(methylnitro-samino)-1-(3pyridyl)-1-butanone which is called as nicotine-derived nitrosamine ketone (NNK) is considered the key ingredient of the tobacco smoke carcinogen that plays an essential role in the carcinogenesis of the lung (Lin et al., 2007).

Several studies that were carried out on the tobacco smoke indicated NNK is considered the only carcinogen induces lung tumors in rats which are similar to human lung adenocarcinoma in the morphology and molecular characters apart from the administration route. NNK is activated by cytochrome P450 enzyme to become the strong carcinogen that attacks DNA leading to gene mutation as a result of DNA adduct formation (Wang et al., 2004).

According to the World Health Organization, many herbs and some plants are used for the treatment of different diseases by $70-80 \%$ of the world population (Shirwaikar et al., 2009). The fruits of physalis peruviana L which are called Cape Gooseberry or Harankash are considered one of these plants that have marked health benefits because it contains high antioxidants, vitamins (A,B, C, E and K), minerals (iron, potassium, phosphorous and zinc), polyunsaturated fatty acids, carbohydrates and fibers. It may be used as antiseptic, diuretic, analgesic, antispasmodic and antiparasitic; it is also used to reduce the weight of the obese persons in the recent years (Hassanien, 2011).

So, the present study aims to evaluate the Physalis Peruviana L effect on lung cancer in rats that result from the toxic effect of nicotine derived nitrosamine ketone (NNK) using pulmonary histopathological, immunohistochemical and DNA flow cytometric analysis.

\section{Materials and Methods}

Sixty healthy adult male Sprague-Dawley rats aged about 16 weeks and weighing $200 \pm 20 \mathrm{~g}$, were obtained from Helwan laboratory farms which is an Egyptian Organization for Vaccine and Biologic Preparations. Rats were housed in a temperature-controlled environment 
$\left(25^{\circ} \mathrm{C}\right)$ and exposed to $12 \mathrm{hr}$ day-night cycles. They had free access to water and food during the experimental period. Animals were acclimatized for one week prior to experiments at the animal house of the Genetic Engineering and Biotechnology Institute, University of Sadat City.

Four groups were formed on a random basis. Each group consists of fifteen rats. The first group (control) received $1 \mathrm{ml}$ of normal saline intra-peritoneal per day while the second received intra-peritoneal two successive toxic doses of NNK (100 mg/kg) dissolved in $1 \mathrm{ml}$ saline within two successive weeks to induce lung tumors in all target rats in this group within 16 weeks after the injection (Mernitz et al., 2009). The third group received intraperitoneal two successive toxic doses of NNK $(100 \mathrm{mg} / \mathrm{kg}$ ) dissolved in $1 \mathrm{ml}$ saline within two successive weeks with a single oral daily dose of Physalis Peruviana L ethanolic extract $(150 \mathrm{mg} / \mathrm{Kg}$ ) by gastric gavage for 16 weeks (Wu et al., 2005). The fourth group received a single oral daily dose of Physalis Peruviana L ethanolic extract $(150 \mathrm{mg} /$ $\mathrm{Kg})$ by gastric gavage for 16 weeks.

4-(methylnitrosamine)-1-(3pyridyl)-1-butanone (NNK) was purchased from Sigma-Aldrich Chemie $\mathrm{GmbH} \mathrm{Co}$., it was in the powder form and dissolved in the normal saline (sodium chloride) $0.9 \%$.

Physalis Peruviana L was obtained from an Egyptian farm, it was selected according to its size and maturation which was determined by its color and clarity. Physalis Peruviana was dried and grinded to a powder form. 100 $\mathrm{mg}$ of the grinding of physalis peruviana $\mathrm{L}$ was taken and soaked with $95 \%$ ethanol for 48 hours with shaking. It was preserved in the refrigerator. Physalis Peruviana L extract was filtered by the filter paper whereas the residue was extracted two additional times and then the filtrates were collected and centrifuged for ten minutes at 3000 round per minute. After that, ethanol was evaporated by evaporator to get the dried powder of physalis peruviana $\mathrm{L}$ whereas $100 \mathrm{gm}$ of this dried powder produced $230 \mathrm{mg}$ (Ramadan, 2012).

\section{Tissue collection}

At the end of experiment (sixteen weeks), the rats were weighed and then sacrificed under diethyl ether anesthesia. Lungs were examined by the naked eye to make sure there is a lung mass or not and then it is removed, washed several times with a physiological saline and then fixed by intratracheal instillation of $10 \%$ neutral buffered formalin. The preserved tissues were dehydrated, embedded in paraffin, sectioned at 3-4 um thickness and stained by haematoxylen and eosin. Microscopic examination was performed to investigate histologically any proliferating lesions in the lung tissues (Bancroft and Gamble, 2002).

\section{Immunohistochemical staining}

Immunohistochemical studies were performed by using the standard avidin-biotin-peroxidase complex (ABC) method. The ki-67 and p53 proteins expression were examined using ki-67 and p53 antibodies with dilution 1: 200 and 1: 100 respectively for 30 minutes at the room temperature (Lab Vision Corporation, USA). According to the manufacturer's specifications, the negative control while the primary antibody was omitted, was included in each set of the experiments. The positive localization result was nuclear staining in two markers (ki-67 and p53). Each section was counted manually at the high power $(400 \times)$ after identification at the low power $(100 \times)$ whereas the representative areas were the highest concentration of stained cells (Cohen et., 1993). About 1000 cells per the slide were counted in each of five microscopic fields from well-labeled areas to determine the average of ki-67 and p53 labeling index (LI) that was expressed as a number of labeled cells (positive for stain) as a percentage of the total number of the counted cells in each specimen. All identifiable staining was regarded as a positive (Mejia et al., 2007).

\section{DNA flow cytometric analysis}

DNA data was obtained from the cell suspensions derived from formalin-fixed, paraffin-embedded specimens, $25 \mu \mathrm{m}$ thick according to the method of Hedley et al., 1989 that was used for the DNA flow cytometric technique. The DNA histogram derived from each specimen was analyzed using DNA analysis software (Cytological software, Coulter Co. Hialeah, Fl, USA). The DNA profile was divided into two groups, diploid and aneuploidy.

\section{Statistical analysis}

Statistical analysis was performed using SPSS version 17. Variability of results was expressed as mean + SD. Results were analyzed by using t-test to investigate the difference among groups. P value of 0.05 was considered statistically significant.

\section{Ethical considerations}

The most appropriate animal species was chosen for this research. Promotion of a high standard of care and animal well-being was done at all times. Appropriate sample size was calculated by using the fewest number of animals to obtain statistically valid results. Painful procedures were performed under anesthesia to avoid distress and pain. Our standards of animal care and administration met those required by applicable international laws and regulations.

\section{Results}

\section{Gross evaluations}

Gross evaluation revealed no nodules formation was observed in the control rat lungs (group 1), and physalis peruviana L treated rats (group 4). Meanwhile, administration of NNK to rats in group 2 produced nodules in all NNK-treated rats with heterogeneity in the morphological appearance of the lesions Figure 1.

\section{1-Effect of NNK and/or physalis peruviana L ethanolic extract on the rats' body weight}

Table 1 represents mean \pm SD values of the body weight in the rats. Mean \pm SD values of the body weight in the control group, second group, third and fourth group were $225.021 \pm 6.032 ; 207.667 \pm 7.301 ; 201 \pm 4.21$ and $226.733 \pm 6.112$ respectively. Value of $P$ indicates a statistical significant difference between groups whereas 


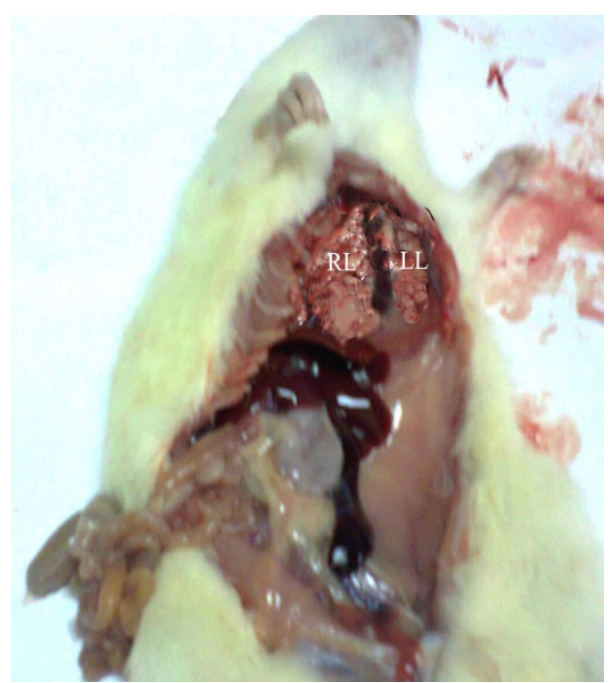

Figure 1. Morphology of the External Surface of Lobes of Both the Right and Lift Lungs Shows most of them were Replaced by Numbers of Firm White Nodules Ranging in Size from $0.2 \mathrm{~cm}$ to $0.5 \mathrm{~cm}$ in Diameter and Projecting from the Lung Surface.

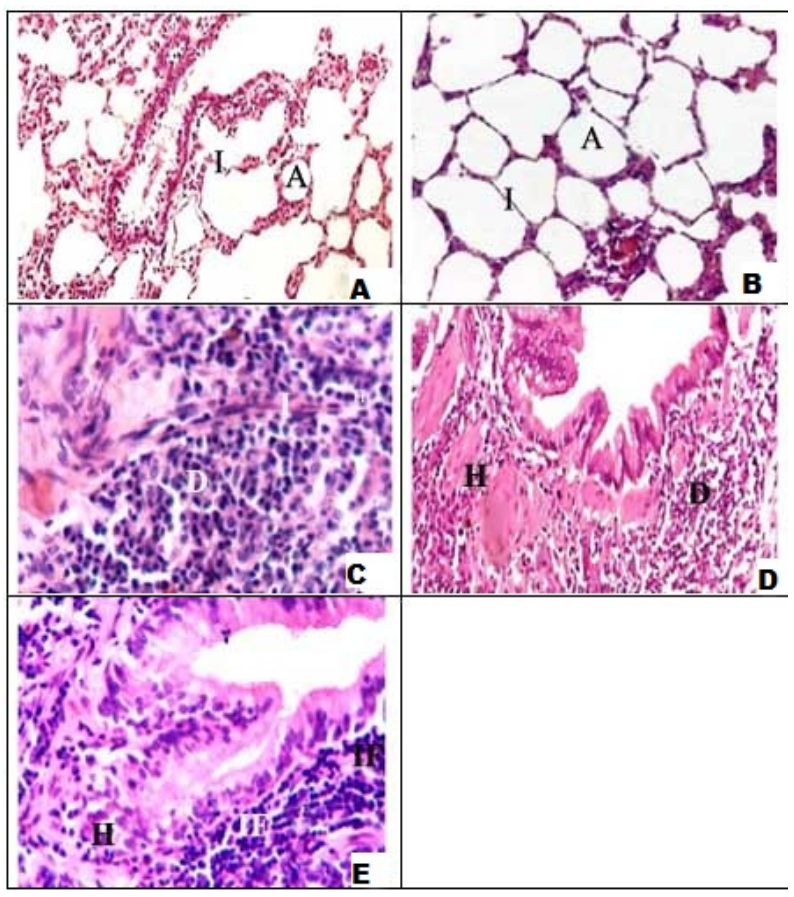

Figure 2. (A) A Photomicrograph of Transverse Section in the Control Group Rat Lung Shows a Normal Architecture of the Alveoli with Thin Inter-Alveolar Septa*; (B) a photomicrograph of transverse section in the fourth group rat lung shows a normal architecture of the alveoli with thin inter-alveolar septa*; (C\&D) a photomicrograph of transverse section in the second group rat lung shows hyperplasia and adenocarcinoma*; (E) a photomicrograph of transverse section in the third group rat lung shows a mild hyperplasia in the epithelial lining and chronic inflammation with the fibrous connective tissues*.*(H\&E X400)

$\mathrm{p}<0.001$, there is a significant decrease in the rats' body weight of the second group which received NNK only in comparison with the control group, while there is a significant decrease in the rats' body weight of the third group which received NNK and physalis peruviana L in comparison with the second group and the control group. There is a significant increase in the rats' body weight of the fourth group which received physalis peruviana L only in comparison with the second group and the third group.

\section{2-Histopathological findings}

Examination of lung section of the control group and physalis peruviana L treated group (fourth group), found unremarkable histopathological abnormalities, Figure 2 (A\&B). However, lung tissues in rats of the second group which received two successive toxic doses of NNK only, showed lesion of adenocarcinoma whereas many bronchioles were denuded of epithelial cells while the remaining Clara and ciliated cells were degenerated with macrophages infiltration in the alveolar spaces, few endothelial and alveolar epithelial cells were degenerated with presence the necrotic cells Figure 2 (C\&D). Conversely, transverse section of the lung tissue in the rats of the third group which received two successive toxic doses of NNK with a single daily dose of physalis peruviana $\mathrm{L}$ ethanolic extract showed a mild hyperplasia in the epithelial lining with the fibrous connective tissue, a numerous clear alveolar cells, congested blood capillaries with macrophages infiltration Figure 2 (E).

\section{3-Immunohistochemical findings}

The immunohistochemical evaluation showed disparity in the positivity of staining among the different groups. The lung sections of the first group (control) rats and the fourth group rats which received physalis peruviana $\mathrm{L}$ ethanolic extract that were stained with $\mathrm{Ki}$ 67 and p53, showed undetectable staining Figure 3 (A \& B). However, there was overexpression of Ki-67 and p53 in the lung section of the second group which received two successive toxic doses of NNK only Figure 3 (C \& D). While a faint staining of Ki-67 and p53 was shown in the lung section of the third group which received two successive toxic doses of NNK with a single daily dose of physalis peruviana L ethanolic extract Figure 3 (E \& F).

\section{4-DNA Flow cytometric analysis in the lung tissues}

In the first group (control), the mean percentage value of the G1-cell constitutes $97.6 \%$, the S-phase cells constitute $0.55 \%$ and the $\mathrm{G} 2$-cells constitute $3.4 \%$ without any sign of aneuploidy. In physalis peruviana $\mathrm{L}$ ethanolic extract group, the main percentage value of G1-cells constitutes $95.22 \%$, the S-phase cells constitute $1.11 \%$ and the G2-cells constitute $2.91 \%$. While the second group which received two successive toxic doses of NNK only shows that there is a decrease in the G1-cells to constitute $39.15 \%$ and an increase in the S-phase cells to $3.2 \%$ with an increase in the G2-cells to $13.22 \%$. On the other hand, The third group which received two successive toxic doses of NNK plus a single daily dose of physalis peruviana L ethanolic extract shows an improvement in the DNA content in comparison with the second group whereas the main percentage value of G1-cells constitutes $89.2 \%$, the S-phase cell constitutes $1.25 \%$ and the G2-cells constitutes 9.3\% with few aneuploidy cells. 
Table 1. Comparison between the Effect of NNK and/or Physalis Peruviana L Ethanolic Extract on Mean+SD of the Rats' Body Weight in the Different Groups

\begin{tabular}{lcccc}
\hline $\begin{array}{l}\text { Group } \\
\text { Statistics }\end{array}$ & $\begin{array}{c}\text { First } \\
\text { Control }\end{array}$ & $\begin{array}{c}\text { Second } \\
\text { NNK }\end{array}$ & $\begin{array}{c}\text { Third } \\
\text { NNK and Physalis } \\
\text { peruviana L }\end{array}$ & $\begin{array}{c}\text { Fourth } \\
\text { Physalis } \\
\text { peruviana }\end{array}$ \\
\hline$\overline{\bar{X}}$ & 225.021 & $207.667 *$ & $201 * *$ & $226.733 * * *$ \\
SD & 6.032 & 7.301 & 4.21 & 6.112 \\
SE & 1.8 & 2.024 & 1.11 & 1.421 \\
T-test & - & 4.959 & 9.381 & 0.059 \\
\hline
\end{tabular}

$\mathrm{SD}=$ Standard deviation; $\mathrm{SE}=\mathrm{Standard}$ error; $* \mathrm{p}<0.001$ (significant difference in comparison with control group); $* * \mathrm{p}<0.001$ (significant difference in comparison with second group); $* * * \mathrm{p}<0.001$ (significant difference in comparison with third group)

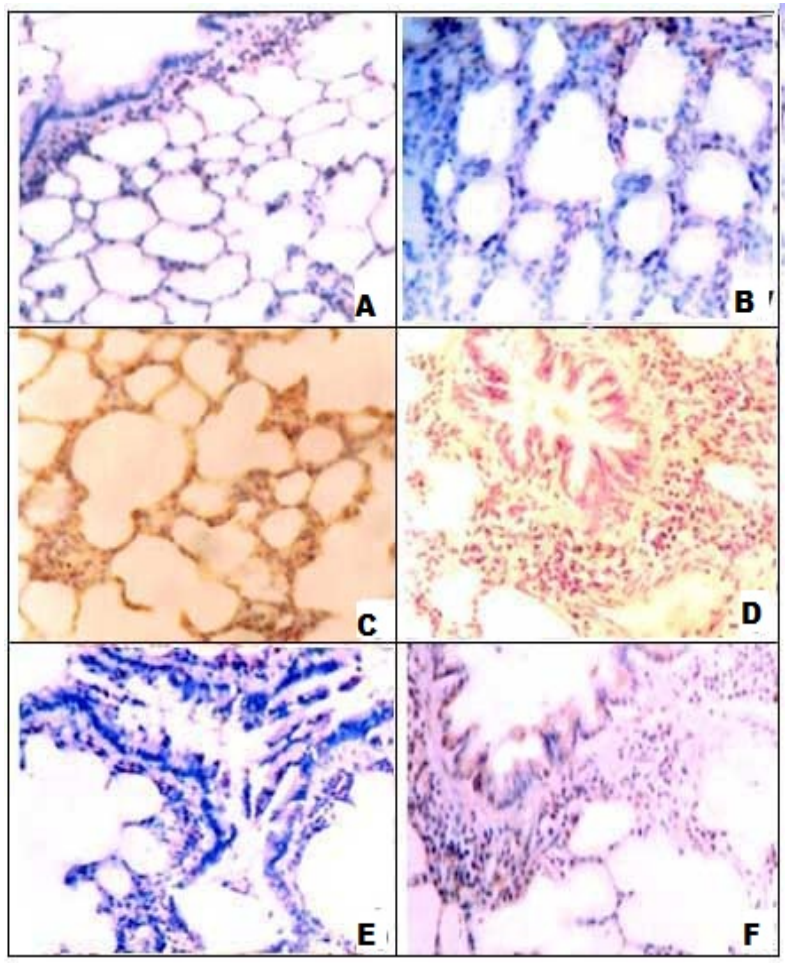

Figure 3. (A) A Photomicrograph of Transverse Section in the Control Group Rat Lung Shows a Negative Staining of ki-67 in the Most of the Lung Cells*. (B) a photomicrograph of transverse section in the second group rat lung shows a strong staining of ki-67 in all lung tissues*; (E) a photomicrograph of transverse section in the third group rat lung shows a faint staining of ki-67 in the lung cells*; (B) a photomicrograph of transverse section in the control group rat lung shows a negative staining of p53 in the most of the lung cells*; (D) a photomicrograph of transverse section in the second group rat lung shows a strong staining of p53 in all lung tissues*; (F) a photomicrograph of transverse section in the third group rat lung shows a faint staining of p53 in the lung cells*. *(Immunohistochemical stain X 40)

\section{Discussion}

Many studies indicated that there is a strong relationship between the prolonged use of the cigarette smoke and the development of the lung cancer because it contains a large number of carcinogens whereas nitrosamine 4-(methylnitro-samino)-1-(3-pyridyl)-1-butanone which is called as nicotine-derived nitrosamine ketone (NNK) is considered as one of the most dangerous carcinogenic compounds of the tobacco smoke (Akopyan and Bonavida, 2006). So the present study recognizes that there is a necessity to limit the lung cancer incidence in the heavy smokers via studying using the natural agents by smokers such as physalis peruviana $\mathrm{L}$ to prevent the toxic effect of NNK on the lung.

In our study we have observed that there was a significant decrease in the rats' body weight of the second group which received NNK only in comparison with the control group and this is due to carcinogenic agent usually affects appetite beside its catabolic effect; this result is in concordance with Phutthaphadoong et al. (2009). But in previous study of Mernitz et al. (2009) who reported that there is no significant difference in the rats' body weight because of the ability of the rats to adjust its dietary intake according to the caloric density of its diet. This statement is in contrary with the present study.

The evaluation of the cellular proliferation marker, $\mathrm{Ki}-67$, and the tumor suppressor gene marker, p53, were shown to be accurate, reliable, and reproducible, the present study indicated that toxic doses of NNK induced the signs of hyperplasia and adenocarcinoma in the lung and this is in harmony with the several previous studies Phutthaphadoong et al. (2009); Isin and Guengerich, (2007) and El-Kenawy (2014), they argued that NNK is a procarcinogen (inactive form) which needs activation to become carcinogen through its hydroxylation in the oxidative metabolism pathway by cytochrome pigment 450 enzymes which are related to CYP multigene family. Another explanation is that NNK could induce oxidative stress (imbalance in the pro-oxidant and oxidative status) this oxidative stress and oxidative damage in turn may be responsible for lung tumor.

The immunohistochemical study showed that toxic doses of NNK induced a strong immunoreactivity in the lung section that is stained with $\mathrm{Ki}-67$ whereas this is an indicator for high lung cell proliferation which is related to occurrence the carcinogenic process in the lung and this is in consistent with Van et al. (2004). It was obvious that administration of physalis peruviana L has ability to retard carcinogenic effect of NNK and result in ablation of the lung lesion growth through scavenging of ROS and inhibitions of the free radical generation then which it may help in suppress the expression of cellular proliferation marker Ki-67, as shown in the present study. Moreover, toxic doses of NNK induced a strong overexpression in the lung section stained with p53 and this is might results from inducing reactive oxygen species "ROS" generation leading to inhibition of the tumor suppressor gene p53 and accumulation of its protein which plays a role in cancer development and this is in consistent with Sung et al. (2011). Whereas, it was shown weak positive staining of p53 and this may be linked to its ability to regulate the expression and activity of cell cycle-related proteins.

In the current work, Flow cytometric analysis for DNA content of the lung tissues detected that DNA index in group 3 were $80 \%$ diploid whereas in group 2 which receive NNK only were $100 \%$ aneuploidy. This is consistent with recent result of Cheng et al. (2015) who refereed that NNK and its metabolites can bind with DNA 
leading to genetic destruction of the lung and mutation with chromosomal changes which are involved in the cell proliferation and differentiation that is critical for initiation the tumor and this finding was supported with our the immunohistochemistry result and is in parallel with the previous finding by EL-Kenawy et al. (2013). This is also consistent with Xue et al. (2014) who confirmed that $\mathrm{NNK}$ is an epigenetic carcinogen leading to uncontrolled cell proliferation in the bronchial epithelium cells with unlimited replication but our results are in contrast with Jin et al. (2004) who presented that NNK inhibits cell apoptosis via modulation of some anti-apoptotic proteins.

Our results showed that administration of physalis peruviana L plus NNK led to ablation of the lung lesion growth; meanwhile, appearance of lesion of mild hyperplasia in few lung tissues rats and a weak positive Ki-67 and p53staining with an improvement in the DNA content in comparison with the second group which received NNK only. This is explained by Chang et al. (2008) who suggested that Physalis peruviana L has antioxidant activity and antiproliferative effects because it contains flavonoids that has anticarcinogenic and antioxidant properties in agreement with Arun and Asha, (2007) who referred that the molecular and biochemical mechanisms of flavonoids have an important role for carcinogenesis inhibition. On the contrary, Puente et al. (2011) confirmed that antioxidant activity of Physalis peruviana $\mathrm{L}$ is not considered the property of one photochemical compound such as flavonoids but it is due to the synergistic effect of different antioxidants such as polyphenols whereas it alleviates the oxidative stress and then it prevents tumor suppressor gene p53 inhibition. According to Reiter et al. (2009), quercetin is considered the main polyphenols in physalis peruviana $\mathrm{L}$ whereas it prevents $\alpha$ hydroxylation of NNK in the liver and the lung beside of cytochrome $\mathrm{P} 450$ activity inhibition, thus it produces protection against NNK induced carcinogenesis by the lipid peroxidation reduction and the decrease of DNA damage in the lymphocytes (Muthukumaran et al., 2008). Moreover, quercetin has also antiproliferative activity through regulation of $\alpha$ 5-and $\alpha$ 9-nicotinic acetylcholine receptors according to Shih et al. (2010).

In conclusion, toxic doses of NNK leads to a high lung cell proliferation and the tumor suppressor gene inhibition based on reactive oxygen species generation inducing pulmonary hyperplasia and adenocarcinoma. Administration of physalis peruviana $\mathrm{L}$ with toxic doses of NNK leads to a mild pulmonary hyperplasia with an improvement in the DNA content because of its antioxidant and antiproliferative effects. The present data add further evidence of physalis peruviana L involvement protection against carcinogenic NNK and may be a viable in therapeutic option.

\section{Recommendations}

According to results of this study, NNK which is considered one of the tobacco smoke components that causes pulmonary tumor. Heavy smokers should use physalis peruviana L to alleviate NNK toxicity induced lung cancer but our results should be verified by performing further researches in humans.

\section{References}

Akopyan G, Bonavida B (2006). Understanding tobacco smoke carcinogen $\mathrm{NNK}$ and lung tumorigenesis. Int J Oncol, 29, 745-752.

Arun M, Asha VV (2007). Preliminary studies on antihepatotoxic effect of Physalis peruviana Linn. (Solanaceae) against carbon tetrachloride induced acute liver injury in rats. $J$ Ethno-Pharmacol, 111, 110-4.

Bancroft JD, Gamble M (2002). Theory and Practice Histological Techniques, 5th ed., Churchill Livingstone. New York, Edinburgh London, 126, 173-5.

Chang JC, Lin CC, Wu SJ (2008). Antioxidative and hepatoprotective effects of Physalis peruviana extract against acetaminophen-induced liver injury in rats. Pharmaceutical Biol 6, 724-31.

Cheng G, Jianmin LI, Zheng M, et al (2015). NNK, a tobaccospecific carcinogen, inhibits the expression of lysyl oxidase, a tumor suppressor. Int J Environ Res Public Health, 12, 64-82.

Cohen GM, Sun XM, Snowden RT, Ormerod MG, Dinsdale D (1993). Identification of a transitional preapoptotic population of thymocytes. J Immunol, 151, 566-74.

EL-Kenawy A, Osman H, Daghestani M (2013). The effect of vitamin $\mathrm{c}$ administration on monosodium glutamate induced liver injury. An experimental study. Experimental Toxicologic Pathol, 65, 513-21.

El-kenawy A (2014). Apoptotic and anti-angiogenic activity of Hypericum perforatum L on 4-(methylnitrosamino)-1-(3pyridyl)-1-butanone-induced lung cancer in rats. Int $J$ Adv Res, 2, 1057-65.

Hassanien MFR (2011). Physalis peruviana: a rich source of bioactive phytochemicals for functional foods and pharmaceuticals. Food Rev Int, 27, 259-73.

Hedley DW (1989). Flow cytometry using paraffin-embedded tissue: Five years on. Cytomet, 10, 229-41.

Isin EM, Guengerich FP (2007). Complex reactions catalyzed by cytochrome P450 enzymes. Biochim Biophys Acta, 1770, 314-29.

Jin Z, Gao F, Flagg T, Deng X (2004). Tobacco-specific nitrosamine 4-(methylnitrosamino)-1-(3-pyridyl)-1butanone promotes functional cooperation of $\mathrm{Bcl} 2$ and c-Myc through phosphorylation in regulating cell survival and proliferation. J Biol Chem, 279, 40209-19.

Lin RK, Hsu HS, Chang JW, et al (2007). Alteration of DNA methyltransferases contributes to 5' $\mathrm{CpG}$ methylation and poor prognosis in lung cancer. Lung Cancer, 55, 205-13.

Mejia C, Navarro S, Llombart-Bosch A (2007). Apoptosis in peripheral neuroblastic tumors. Immunohistochemical expression of bcl-2 and $\mathrm{p} 53$ is related to DNA fragmentation. Histol Histopathol, 22, 1365-70.

Mernitz H, Lian F, Smith DE, Meydani SN, Dong Wang X (2009). Fish oil supplementation inhibits NNK-induced lung carcinogenesis in the A/J Mouse. Nutr Cancer, 61, 663-9.

Muthukumaran S, Sudheer AR, Nalini N, Menon VP (2008). Effect of quercetin on nicotine-induced biochemical changes and DNA damage in rat peripheral blood lymphocytes. Redox Rep, 13, 217-24.

Phutthaphadoong S, Yamada Y, Hirata A, et al (2009). Chemopreventive effects of fermented brown rice and rice bran against 4-(methylnitrosamino)-1-(3-pyridyl)-1butanone-induced lung tumorigenesis in female $\mathrm{A} / \mathrm{J}$ mice. Oncol Reports, 21, 321-327.

Puente LA, Pinto-Munoz CA, Castro ES, Cortes M (2011). "Physalis peruviana Linnaeus, the multiple properties of a 
highly functional fruit: a review. Food Res Int, 44, 1733-40.

Ramadan MF (2012). Physalis peruviana pomace suppresses highcholesterol diet-induced hypercholesterolemia in rats. Grasas Y Aceites, 63, 411-22.

Reiter M, Rupp K, Baumeister P, Zieger S, Harreus U (2009). Antioxidant effects of quercetin and coenzyme Q10 in mini organ cultures of human nasal mucosa cells. Anticancer Res, 29, 33-9.

Shih YL, Liu HC, Chen CS, et al (2010). Combination treatment with luteolin and quercetin enhances antiproliferative effects in nicotine-treated MDA-MB-231 cells by down-regulating nicotinic acetylcholine receptors. J Agric Food Chem, 58, 235-41.

Shirwaikar A, Verma R, Lobo R (2009). Phytotherapy-safety aspects. Natural Product Radiance, 8, 55-63.

Sung AN, Kang JH, Kim DH, Lee MS (2011). Vitamin C increases the apoptosis via up-regulation p53 during cisplatin treatment in human colon cancer cells. BMB Rep, 44, 211-6.

Van Diest PJ, Van Der Wall E, Baak JP (2004). Prognostic value of proliferation in invasive breast cancer: a review. J Clin Pathol, 57, 675-81.

Wang Y, Zhang Z, Yan Y, et al (2004). A chemically induced model for squamous cell carcinoma of the lung in mice: histopathology and strain susceptibility. Cancer Res, 64, 1647-54.

Wu SJ, Ng LT, Huang YM (2005). Antioxidant activities of physalis peruviana. Biological Pharmaceutical Bulletin, 28, 963-966.

Xue J, Yang S, Seng S (2014). Mechanisms of cancer induction by tobacco-specific NNK and NNN. Cancers, 6, 1138-56. 